\title{
ANIRIDIA, GLAUCOMA CONGÉNITO, CÓRNEAS OPACAS EN RECIÉN NACIDO
}

\author{
ANIRIDIA, CONGENITAL GLAUCOMA AND WHITE CORNEAS \\ IN A NEWBORN BABY
}

\author{
DIAGO T ${ }^{1}$, HARTO $\mathrm{M}^{2}$, SERRA $\mathrm{I}^{2}$, PARDO D ${ }^{1}$, MONTERO J ${ }^{1}$, DÍAZ-LLOPIS $\mathrm{M}^{2}$
}

\begin{abstract}
RESUMEN
Caso clínico: Presentamos el caso de un recién nacido en el que observamos aniridia, glaucoma congénito y corneas edematosas, sin aclaramiento de la córnea tras cirugía de glaucoma, en el que se plantea una queratoplastia. No presenta patología sistémica acompañante ni deleción del cromosoma 11.

Discusión: Es importante realizar una buena exploración oftalmológica y sistémica en pacientes recién nacidos con aniridia, debido a la patología que pueden asociar. Presentamos un caso tan poco frecuente, en el que coexisten aniridia, glaucoma congénito y córneas opacas en un recién nacido tan sólo referenciado dos veces anteriormente en la literatura según nuestro conocimiento.
\end{abstract}

Palabras clave: Aniridia, glaucoma, córnea, recién nacido.

\section{INTRODUCCIÓN}

La aniridia es una enfermedad poco frecuente, normalmente bilateral, que se caracteriza por una hipoplasia del iris $(1,2)$. La prevalencia es de 1 caso cada 50.000 a 1 caso cada 100.000 (3).

La aniridia es de herencia familiar en dos tercios de los casos, con transmisión autosómica dominan-

\begin{abstract}
Case report: We present the case of a newborn baby in whom we observed aniridia, congenital glaucoma and edematous corneas, without clearance of the cornea after glaucoma surgery, and in whom a keratoplasty was considered. The patient had no evidence of systemic diseases and no deletion of chromosome 11.

Discussion: It is important to perform a thorough ophthalmological and systemic exploration in newborn patients with aniridia due to other diseases that can be associated with it. We present the unusual case in which aniridia, congenital glaucoma and white corneas coexisted in a newborn baby. To our knowledge, such cases have only been reported twice before in the literature (Arch Soc Esp Oftalmol 2009; 84: 573-576).
\end{abstract}

Key words: Aniridia, glaucoma, cornea, newborn.

te y penetrancia completa. El gen que se afecta en la aniridia familiar es el PAX6 en la rama corta del cromosoma 11 (1).

Al practicar una gonioscopia observaremos un muñón rudimentario de iris, incluso en los casos más extremos. En estos pacientes suele ser frecuente la asociación a una hipoplasia foveal e hipoplasia del nervio óptico.

\footnotetext{
Recibido: 19/10/08. Aceptado: 23/11/09.

Hospital La Fe. Valencia. España.

${ }^{1}$ Licenciado en Medicina.

2 Doctor en Medicina.

Correspondencia:

Teresa Diago

C/. Dr. Gómez Ferrer, 11, pta. 10

46010 Valencia

España

E-mail: tediasem@gmail.com
} 
Progresivamente también son comunes la aparición de cataratas, glaucoma y opacidad de la córnea. El glaucoma suele presentarse con el tiempo debido al cierre progresivo del ángulo conforme éste se va ocluyendo por el muñón rudimentario de iris. La córnea progresivamente puede verse afectada e ir opacificándose. Es rara la presencia de glaucoma y opacificación corneal en el momento del nacimiento en pacientes con aniridia $(1,2)$.

\section{CASO CLÍNICO}

\section{Antecedentes personales}

Paciente varón nacido mediante cesárea (embarazo controlado, no infección prenatal ni perinatal) a las 36 semanas de gestación.

El paciente fue derivado a nuestro centro por sospecha de glaucoma congénito bilateral a los tres días del nacimiento.

\section{Exploración oftalmológica}

A la exploración oftalmológica bajo anestesia general se objetivó una presión intraocular de $27 \mathrm{mmHg}$ mediante tonometría de Perkins en ambos ojos, un diámetro corneal de 11,5 mm, una gran opacidad corneal y una aniridia bilateral.

\section{Tratamiento}

Se procedió a la realización de una trabeculectomía bilateral a las XII, con colgajo escleral triangular y colgajo conjuntival con base en fórnix. No se utilizó ningún antimitótico.

\section{Evolución}

A los 15 días se le realizó una exploración oftalmológica bajo sedación en la que se apreciaba una persistencia de la opacidad corneal (figs. 1 y 2) y una presión intraocular de $17 \mathrm{mmHg}$ en ojo derecho y de $14 \mathrm{mmHg}$ en ojo izquierdo.

Se plantea la posibilidad de practicar una queratoplastia, debido a la persistencia del edema corneal en ambos ojos.

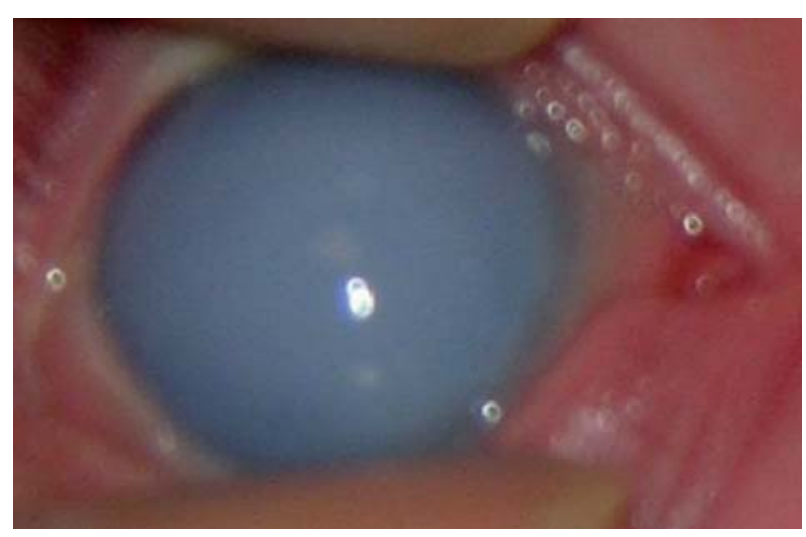

Fig. 1: Ojo derecho tras un mes de la trabeculectomía.

\section{Estudio genético}

Se valoró la presencia de posibles deleciones o duplicaciones genéticas mediante la técnica MLPA (Multiples Ligation-dependent Probe Amplificaction), empleando la mezcla de sonda SALSA P245. Este método permite valorar, entre otros, la dosis del gen PAX 6 en la región cromosómica 11p13, cuya deleción ocasiona aniridia y otras alteraciones oculares.

Todas las sondas empleadas mostraron una intensidad relativa normal en la muestra estudiada, por lo que se descartó que el paciente presentara la deleción que predispone al síndrome WAGR.

\section{DISCUSIÓN}

La aniridia es una enfermedad poco frecuente que se caracteriza por un iris hipoplásico y que puede asociarse a otras anomalías oculares como hipo-

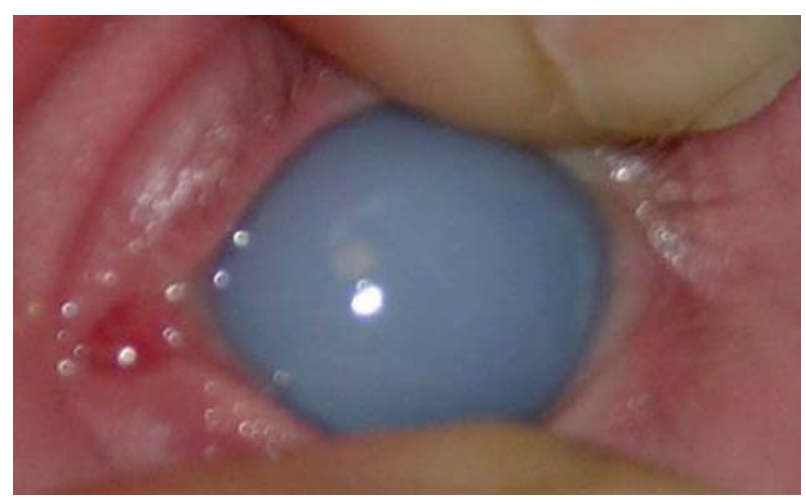

Fig. 2: Ojo izquierdo tras un mes de la trabeculectomía. 
plasia de nervio óptico, hipoplasia foveal, cataratas, glaucoma y puede también asociarse a alteraciones sistémicas tales como anomalías en el aparato genitourinario, tumor de Wilms y retraso mental, dando lugar al llamado síndrome de WAGR (tumor de Wilms, aniridia, alteraciones en el aparato genitourinario y retraso mental).

Es una enfermedad congénita cuya presentación puede ser esporádica o hereditaria familiar. El gen defectuoso es el PAX6, encargado del desarrollo ocular, presente en el cromosoma 11p13 (4).

$\mathrm{Al}$ realizar una búsqueda bibliográfica en MEDLI$\mathrm{NE}$ aparecen tan sólo 2 referencias que presenten todas las características oftalmológicas de nuestro paciente: Aniridia, córneas edematosas y glaucoma congénito en recién nacido $(3,5)$. Lee et al presentan un caso con las características anteriormente citadas en un paciente con síndrome de Brachmann-de Lange (síndrome Cornelia de Lange), el cual pertenece al grupo de síndromes con múltiple anomalías congénitas y retraso mental. El paciente del que hacen mención fue sometido a múltiples cirugías: válvula de Ahmed, queratoplastias penetrantes. Este paciente a la edad de 5 años y medio de edad consiguió una córnea transparente en un ojo y una ambliopía en el contralateral debido a un fallo en el injerto debido a infecciones recurrentes (5).

Lise-Schneider B et al muestran el caso de dos hermanas en el que una de ellas presentaba un glaucoma congénito con edema corneal y aniridia bilateral, no teniendo afectado el PAX6, y la otra hermana presentaba un glaucoma congénito con edema corneal sin aniridia (3).
En nuestro caso, la tensión ocular se mantiene controlada, pero dicho control no ha tenido ningún efecto sobre el aclaramiento de la córnea, por lo que el edema corneal creemos que es debido a una anomalía corneal asociada a la aniridia.

En los pacientes afectos de aniridia la queratopatía suele aparecer en la infancia tardía, no en el nacimiento. Esta situación es debida a una insuficiencia de las células madre limbares dando lugar a la imposibilidad de regeneración del epitelio corneal, produciendo una vascularización de la córnea y un tapizado de la misma por epitelio conjuntival (2).

Se plantea la posibilidad de realizar una queratoplastia dada la afectación central de ambas córneas.

\section{BIBLIOGRAFÍA}

1. Wright KW, Spiegel PH. Oftalmología pediátrica y estrabismo. Los Requisitos en Oftalmología. Barcelona: Harcourt; 2000; 56-66.

2. Simon JW. Pediatric Ophthalmology and Strabismus. Basic and Clinical Science Course. Singapore: American Academy of Ophthalmology; 2007; 200-202.

3. Lise-Schneider B, Calvas P, Roche O, Lambert JC, Dufier $J$ L, Costet-Fighiera C. Glaucoma with aniridia and isolated congenital glaucoma in siblings: contribution and limits of genetics. J Fr Ophthalmol 2007; 30: 44-48.

4. Robinson DO, Howarth RJ, Williamson KA, Van Heynigen $V$, Beal SJ, Crolla JA. Genetic analysis of chromosome 11 p13 and the PAX6 gene in a series of 125 cases referred with aniridia. Am J Med Genet A 2008; 146: 558-569.

5. Lee WB, Brandt JD, Mannis MJ, Huang CO, Rabin GJ. Aniridia and Brachmann-de Lange syndrome: a review of ocular surface and anterior segment findings. Cornea 2003; 22: 178-180. 